\title{
Entrevista a Josep M. Català: de lo melodramático al relativismo: apuntes sobre la naturaleza del documental
}

\author{
Eduardo Tulio Baggio \& Rafael Tassi Teixeira*
}

Lugar y fecha de la entrevista: Curitiba/PR, el 22 de octubre de 2016.

En una mañana fresca de otoño curitibano, nos encontramos con el profesor Josep Maria Català para hacerle una entrevista, aprovechando su presencia como uno de los conferenciantes del XX Encuentro de SOCINE (Sociedad Brasileña de Estudios de Cine y Audiovisual). La entrevista tuvo lugar en el Bosque João Paulo II - que lleva ese nombre porque fue inaugurado después de la visita del papa João Paulo II a la ciudad en 1980 - un área verde donde todavía se conservan algunas antiguas casas polacas, construidas en madera al estilo de la segunda mitad del siglo XIX y que han sido mantenidas como un homenaje a los inmigrantes de aquel país que llegaron a Curitiba alrededor de 1870.

El profesor Josep Maria Català tiene una larga trayectoria en estudios de cine y, en especial, en los estudios del documental. Doctor en Ciencias de la Comunicación por la Universidad Autónoma de Barcelona y con maestría en Fine Arts in Film Theory por la Universidad de São Francisco, Califórnia. Es catedrático de Comunicación Audiovisual en la UAB, donde enseña Estudios Visuales y es director académico del Máster en Teoría y Práctica del Documental Creativo. Es autor y organizador de varios libros. Entre ellos: Imagen, memoria y fascinación: notas sobre el documental en España (co-editado con Josetxo Cerdán y Casimiro Torreiro - Ocho y Medio, 2001) La puesta en imágenes: conceptos de dirección cinematográfica (Paidós, 2001), La forma de lo real: introducción a los estudios visuales (Editorial de la Universitat Oberta de Catalunya, 2008) y La imagen interfaz: representación audiovisual y conocimiento en la era de la complejidad (Universidad del País Vasco - Argitalpen Zerbitzua Servicio Editorial, 2010).

Los puntos de interés para esta entrevista fueron el concepto de lo melodramático en el cine documental y como éste puede ser entendido en las pelí-

* Eduardo Tulio Baggio: Universidad Estadual de Paraná - UNESPAR, Centro de Artes, Curso de Cine y Audiovisual. 80035-050, Curitiba, Brasil. E-mail: baggioeduardo@gmail.com

Rafael Tassi Teixeira: Universidad Tuiuti de Paraná - UTP, Programa de Posgrado en Comunicación y Lenguajes, Mestrado y doutorado en Comunicación y Lenguajes. 82010-330, Curitiba, Brasil. E-mail: rafatassiteixeira@ hotmail.com 
culas ante la premisa ética propia del documentalismo. El documental español, partiendo de algunos filmes de carácter hibrido con la ficción, es otro asunto abordado para tratar de ejemplos relacionando documental y melodrama. Hablamos un poco también sobre el relativismo y la expansión del documental hacia otros medios como la web. Señalamos grandes marcos de la cinematografía española documental y algunas películas contemporáneas.

Josep Maria Català nos ofrece la oportunidad de pensar el cine documental de manera impar, con aportes que sustentan una original visión sobre este tupo de cine que permite la apertura de caminos de pensamiento e investigación extremamente amplios.

Eduardo Baggio: La idea de lo melodramático con documental. ¿Cómo puede pensarse el melodrama, como es conocido en la ficción, en un documental?

Josep M. Catalá: La idea proviene de un libro que publiqué hace unos años, en donde hablaba de un nuevo realismo. Creo que el arte ha llegado a un punto en el que está muy claro que las vanguardias están agotadas, y aparece, por el contrario, un ansia de realismo, un regreso multifacético al realismo. Se trata de un fenómeno que no solo afecta al arte, sino que es más general. Lo que puede distinguir este nuevo realismo del realismo anterior es un interés por expresar visualmente las emociones, de ahí la idea de calificarlo de melodramático. $\mathrm{Y}$ en todo esto yo presentía que el documental tenía un papel muy importante.

Teniendo en cuenta la revolución que tuvo lugar en los años 90 con el surgimiento de las nuevas formas documentales, que se inició con un giro subjetivo, empecé a pensar que podríamos hablar de un documental melodramático - el melodrama no deja de ser un realismo exagerado, o mejor dicho, acrecentado. Creí que era una manera de poder detectar nuevas facetas en esta clase de cine, no necesariamente porque hubiera una escuela de documentalistas que trabajasen con este tipo de documentales melodramáticos - aunque los hay, pensemos en el famoso Tarnation (2003), de Jonathan Caouette, convertido en prototipo, o, sin ir más lejos, Bus 174 (2002), de José Padilha y Felipe Lacerda, o ese sugestivo experimento de Eduardo Coutinho que es Jogo de Cena (2007) -, sino porque los nuevos documentales mostraban, de alguna forma u otra, un interés por incorporar el factor emocional en su desarrollo de forma expresa. Concebí mi idea sobre la posibilidad de un documentalismo melodramático pensando principalmente en Tartation, ya que se trata de un documental realmente muy emocional y visualmente exagerado. A partir de ahí, fui rastreando una serie de producciones que podían estar incluidas en este género tan paradójico y, 
en principio contradictorio, si tenemos en cuenta que el documental siempre se ha considerada el prototipo de un cine objetivo por naturaleza...Pero estas contradicciones también sirven para reflexionar.

E. B.: Sobre esta misma idea: en este tipo de documentales donde hay melodrama, ¿podría haber algún tipo de compromiso ético en relación al abordaje del mundo?

J. M. C.: Yo creo que sí. Lo que distingue al cine documental es precisamente esta cuestión ética. Lo que ocurre es que las cosas se han complicado mucho y el ámbito del compromiso ético ya no tiene unos perfiles tan claros como al principio, cuando los documentalistas clásicos se expresaban a través de un discurso de sobriedad y de compromiso que se daba prácticamente por sentado. Hoy en día este compromiso ético hay que trabajarlo, no es una cuestión de principios. Por ejemplo, ahora se habla mucho de posverdad, el concepto se ha puesto súbitamente de moda en la política, sin que se repare en que fue en el campo de documental donde se empezó a hablar de posverdad no para amparar la mentira, sino para expresar la necesidad de desactivar los dogmatismos. La verdad no existe, lo que existe es la mentira. La mentira es un acto voluntario, que se efectúa a conciencia, mientras que la verdad es siempre discutible. Solo con esto, la perspectiva ética se complica enormemente y nos obliga a adoptar una mirada compleja sobre la realidad.

Rafael Tassi: En la Historia del documental en España, ¿qué papel juega el documental hibrido a partir de la década de los 90 ?

J. M. C.: No han desaparecido los documentales clásicos, ni los sociales, sino que a partir de los 90 digamos que ha habido una transformación del documental al surgir unos intereses que estaban generalmente apartados de este tipo de cine, Me refiero en especial a la subjetividad, que se ha acabado mezclando con todo lo demás. En España, entre los años 50 y 70, las cosas estaban mucho más claras, ya que existía prácticamente una sola vía, que era la del documental tradicional, en su mayoría de carácter político e incluso militante (de testimonio social, antifranquista). Lo demás, pertenecía al régimen o a sus aledaños. Por otra parte, hay que tener en cuenta que el documental social, aunque no tuviera un contenido específicamente político, siempre se situaba al margen del discurso oficial, y, por tanto, también era político. Es decir que predominaba la vía política para contrarrestar la cinematográfica franquista: se trataba, en gran parte, de un cine clandestino. Existía también una corriente experimental, especialmente en la llamada Escuela de Barcelona de finales de los años sesenta, derivaba de la corriente tradicional. Todo confluía, sin embargo, en la propuesta política, ya que, en una dictadura, cualquier iniciativa 
va forzosamente en contra de lo establecido. Es a partir de los años 90, en otra situación completamente distinta, cuando las formas empiezan a combinarse: por ejemplo, las del documental experimental y las del social, lo que hace que este sea mucho más estético, es decir, que la estética sirva para expresar facetas de la realidad que, antes, por ese discurso de sobriedad parecían postergadas. Aunque se siguen haciendo estos documentales más sociales, mas testimoniales.

La crisis del documental clásico se inició cuando la televisión vino a ocupar su lugar. Si se trataba de captar y dar testimonio de la realidad, eso la televisión lo hacía de forma más directa e inmediata, aunque también más superficialmente. Por tanto, dejó de haber un público específico para el cine documental, un público que saciaba su interés con lo que la televisión le ofrecía. En general la televisión eliminó, en su momento, la necesidad de este tipo de documentales, pero de alguna forma volvió a reinventarlos porque a partir de los años 80-90, aparecen muchos canales temáticos que precisan material para sus emisiones, lo que hace que las productoras vuelvan a interesarse por los documentales. Pero los circuitos de distribución de los nuevos films documentales superan el ámbito televisivo y se centran en los innumerables festivales, luego llegan quizá a los museos o a centros culturales y, en algún caso concreto, al cine. Es decir que el cine ya no es el ámbito de exhibición hegemónico como fue durante la primera época del documental clásico, la anterior a la televisión.

E. B.: La presencia intensa del realismo que se percibe en los últimos años, tanto en la ficción como en la TV. En tu opinión, ¿puede confundir al realismo que antes era más claro en la historia del cine y puede comprometer la tradición realista?

J. M. C.: Lo cierto es que el concepto se presenta muy confuso, no está tan claro qué es el realismo. Pero yo creo que no es que haya una verdadera confusión, sino que ahora somos más conscientes de que las fronteras no están tan bien delimitadas como antes. Nos hemos dado cuenta de que estábamos equivocados sobre la pureza del documental clásico porque ¿dónde estaban las fronteras entre realidad y ficción en los documentales de John Grierson o de Basil Wright (que son maravillosos)? Estos documentales los ves ahora y te das cuenta de que el tipo de imagen, el tipo de encuadre es muy parecido a los del cine de ficción de la época. Además, había en ellos un componente narrativo aunque estuvieran reflejando acciones que supuestamente eran reales, no solo realistas. Pensemos en Drifters (John Grierson, 1929) o en Night Mail (Basil Wright e Harry Watt, 1936)... La diferencia entre una película de ficción y un documental consistía en lo siguiente: el cine de ficción partía de un hecho ficticio y lo llevaba al realismo, a la verosimilitud. Por su parte, el 
documental partía de una realidad e iba evolucionando hacia la ficción, hacia las formas del cine de ficción. No ha habido, en el cine clásico, documentales tan estrictamente realistas como parece. Estos aparecieron luego con el cine de Frederick Wiseman el llamado direct cinema que pretendía eliminar el factor narrativo.

En definitiva, ahora todo parece más confuso pero es porque se han eliminado las fronteras. Antes vivíamos en una época neoclásica donde estaba todo muy claro y perfectamente clasificado y ahora estamos en una época neobarroca en la que todo se mezcla. Es un momento peligroso porque si te dejas llevar por esta confusión puedes perder la idea de lo que estás haciendo.

También es verdad que tienes a tu disposición muchos más instrumentos para emplearlos en investigar. La diferencia está ahí. Antes se trataba de dar testimonio de una realidad; ahora se trata de investigar esa realidad. En última instancia hay un intento de hacer preguntas sobre la realidad, pensar esa realidad.

R. T.: Hay documentales en la historia de España que son un marco, como los de Guerín (En Construcción, José Luis Guerín, 2001) pero ¿que podrías decirme sobre el documental de Erice El sol del membrillo (Victor Erice, 1992)?

J. M. C.: Se trata de una película fundamental. Plantea muchos problemas sobre el tiempo: el tiempo y el cine, el tiempo y la pintura, la percepción y la memoria...

Erice es un director muy minucioso...pero no se prodiga demasiado. La aparición de sus obras va marcando diferentes etapas en el cine español pero, como no las prolonga, como tarda mucho en hacer otra película, su producción no cuaja tanto como las de otros directores (Guerín). Tiene otras películas documentales que no son tan conocidas como esta, por ejemplo, La Mort Rouge o La muerte roja (Victor Erice, 2006). Es gran medida autobiográfica. En ella Erice habla de sí mismo, de su infancia y de cómo le marcó una película de Sherlock Holmes que vio cuando era niño, La muerte roja. A partir de ella, deja que sus fantasmas regresen a la realidad. La rodó con motivo de una exposición y por eso solo se ha distribuido en DVD, después de ser exhibida en la misma. Esa exhibición planteaba un encuentro entre Kiarostami y Erice. Constaba de fotografía, algunas películas, y cartas videográficas que habían intercambiado ambos directores.

La filmografía de Erice es importantísima, no solo destacan sus documentales, que son pocos. Películas como El Espíritu de la Colmena (1973) o El Sur (1983) son también relevantes para comprender la idea que el director tiene de las relaciones del cine con la realidad... Se pueden detectar una serie de conexiones muy estrechas e interesantes entre los postulados de Guerín y de 
Erice, algo que no se refiere tan solo a la obra de ambos, sino que tiene que ver también con su discurso sobre el cine: cuando coinciden en una conferencia, por ejemplo, ambos adoptan una cierta actitud transcendental sobre el cine en general y el documental en particular que hace que sea siempre un evento muy peculiar, casi de carácter religioso o místico. El documental más conocido de Guerín, que en España fue un boom, es En construcción (2001), pero ya había hecho una película antes, Tren de sombras (1997) realmente transcendental: se trata de una mezcla de documental y ficción, o sea, un falso documental que es absolutamente melodramático. Lo digo para abundar en mi idea anterior. Este falso documental que además falsifica una película supuestamente encontrada se plantea cómo a través del celuloide se puede reconstruir un mundo emocional desparecido. Y a partir de ahí surge una historia que no solo parece verdadera, sino que puede decirse que es verdadera como lo es una novela, solo que, en este caso, los procedimientos son intrínsecamente cinematográficos, incluso podríamos decir de un esencial documentalismo. Es una película apasionante.

R. T.: Hablando de la figura de Llorenç Soler, ¿cuál sería la aportación de Soler en la historia del documental en España?

J. M. C.: La primera parte de su trabajo tuvo mucha influencia en un sector del documentalismo español. Se trataba, en general, de documentales de tema social. Luego se retiró parcialmente de la circulación. Siguió haciendo algunos films de encargo, aunque no por ello menos personales e interesantes, pero principalmente se dedicó a hacer pequeños ensayos fílmicos muy particulares que circularon casi de forma privada.

Yo creo que la historia del documental español a partir de los años 80 está por hacer. En ese período aparecieron muchos documentalistas jóvenes, muy activos pero que son poco conocidos. Entre ellos, se podría colocar Soler, no tanto por juventud como por su incesante actividad.

Por otro lado, había que plantearse la historia del cine de una forma distinta ya que, hasta ahora, nos hemos referido principalmente a un cine que podríamos denominar proyectado; pero este tipo de exhibición ya no tiene tanta importancia; no es fácil controlar cómo se ven los documentales actuales. En el futuro, habrá que ver cuál va a ser el eje que va a organizar los trabajos de investigación sobre cine, ya que hay muchas obras no exhibidas, que solo llegan a festivales, que circulan por Internet o de mano en mano, pero que son cruciales para entender la historia contemporánea de este tipo de cine.

E. B.: En relación a tu discurso sobre la expansión del documental: la manifestación del documental en otros medios, en otros lenguajes ¿sería una 
continuidad de la tradición documental o podríamos considerarlo como un nuevo camino?

J. M. C.: Yo creo que es una continuación de la tradición del documental o una derivada del mismo...

Desde los inicios, se establecieron tres corrientes muy claras en el cine: 1) ficción; 2) documental; 3) Vanguardia.

Y luego, claro, aparecieron algunas mezclas pero que no dejaban de ser la excepción. En algún momento estas tres vertientes se empiezan a combinarse sin prejuicios y es entonces cuando nos preguntamos si ha desaparecido el documental. La respuesta es que no. ¿Ha desaparecido el cine de ficción, o el de vanguardia? No, tampoco han desaparecido. Lo que pasa es que ha producido una nueva situación que se distingue por el realismo básico del documental, es decir, el interés por la realidad. Ello hace que sea interesante examinar la situación presente de la creación estética en general desde la perspectiva del cine documental, ya que es a través de este que se resuelven las contradicciones de las vanguardias: hace tiempo que las vanguardias han quedado reducidas a un juego, Hay veces, en la actualidad, que no se sabe muy bien lo que el artista pretende expresar a través de sus obras. Algunas instalaciones presentadas en certámenes internacionales o en museos de arte contemporáneo parecen, en este sentido, simplemente ridículas. Pero, si contemplamos el problema desde el punto de vista de que no se trata tanto de una propuesta estética en sí, sino de investigar sobre la realidad, habríamos decantado el problema hacia la tradición documentalista, que de esta manera se manifestaría incluso fuera del ámbito específico del documental.

R. T.: Eso sería también una dificultad del "amateur" para saber dónde se ubica.

J. M. C.: Exactamente. Antes el "amateur" se suponía que era un artista poco comprometido con su obra, un aficionado. Su ambición no era muy grande y, por ello, los cineastas amateurs se conformaban con hacer un cine de segunda categoría. Era una forma de hacer cine: películas amateur. Existía una separación muy grande entre las películas amateur y las películas profesionales, que los amateurs aceptaban como algo natural. Ahora, con los nuevos instrumentos tecnológicos, esta separación ha desaparecido, ya no hay excusa para no hacerlo lo mejor posible. El cineasta se ha transformado en algo parecido a un escritor, en el sentido de que tiene una relación con la obra mucho más directa que antes. Puedes seguir teniendo un gran equipo a tu alrededor para rodar una película pero, en realidad, no lo necesitas. Puedes salir solo con tu cámara, grabar y luego montar las imágenes en casa, y lo puedes hacer de 
una forma prácticamente profesional. Ya no existe la excusa de que no se ha hecho mejor porque no había medios...si no se ha hecho mejor, es porque no se tiene el talento o la voluntad suficiente.

E. B.: En el pensamiento académico, existe, hoy en día, un relativismo muy fuerte, ese relativismo puede ser importante y al mismo tiempo dificultador? Al pensar, por ejemplo, en Erick Barnouw que clasificaba muy bien los tipos de documental (social, publicitario, etc).

J. M. C.: No cabe duda de que las clasificaciones son necesarias para poder orientarse. Pero, si no se relativizan, existe el peligro de no ver nada que no esté previamente clasificado. Yo, que soy bastante contrario a las clasificaciones, me he visto obligado a organizar las tendencias del documental contemporáneo con un cierto rigor para poder expresar claramente mis ideas respecto al mismo. He planteado la existencia de una serie de giros: subjetivo, reflexivo (ensayo), emocional (el documental melodramático) e imaginario. Este último delimita, de alguna forma, esas extensiones del documental que lo llevan hacia otra parte. Me refiero a la WEB documental o docuweb (documental interactivo), el documental de realidad virtual o documental inmersivo, el documental de animación, el comic documental...con ello se están abriendo nuevos campos inimaginables hace poco, campos que hay que teorizar porque muchos de ellos resultan paradójicos si se contemplan desde la perspectiva de la mentalidad del documental clásico..

Hoy en día, hay documentales de todo tipo y se pueden realizar desde muchas vertientes: un diseñador gráfico por ejemplo puede hacer documentales desde su campo, como también puede hacerlos un dibujante, o un viajero, hacer la crónica de sus viajes a través de un cómic, pongamos por caso...

Todo esto me sirve a mí para poner orden. Aunque realmente es muy difícil hacer una clasificación única ya que un documental puede pertenecer a varios grupos a la vez. Se deben hacer clasificaciones que no sean totalmente estrictas, clasificaciones provisionales, tentativas. Vivimos momentos difíciles para la simplicidad. No se pueden hacer clasificaciones taxativas porque estaríamos dejando fuera muchas cosas.

E. B.: Este relativismo puede ser perjudicial? Por ejemplo, cuando se dice que Todo puede ser, al mismo tiempo Nada puede ser. El cine nacional puede haber sido hecho por gente de fuera, quien colaboró, de donde vino la influencia...

J. M. C.: El relativismo, que tiene muy mala prensa, pero es algo que todos practicamos aunque nadie quiera reconocerlo. Al fin y al cabo, relativismo no quiere decir más que consideramos que todo es susceptible de ser investigado. 
El relativismo surge de la curiosidad y se alimenta de la imaginación. No es nada conveniente determinar a priori aquello por lo que debemos interesarnos, a partir de una decisión, generalmente establecida por otros, sobre qué es y que no es factible, verdadero o productivo.

Descubrí hace poco a un antropólogo brasileño (Eduardo Viveiros de Castro) que habla del perspectivismo de una manera muy interesante. Considera que el pensamiento indígena puede ser tan importante como el pensamiento colonial y que además se mezclan y se retroalimentan. ¿Esto es relativismo o es realismo?

R. T.: Antiguamente era más fácil hacer antropología porque la idea del contraste estaba fijada y hoy en día es más complicado.

J. M. C.: Si, volviendo otra vez a la ética, hoy esto te obliga a ser más consistente, tu compromiso tiene que ser mucho más firme. A cada momento, te ves obligado a tomar decisiones, sin recurrir a las que ya han tomado otros. Mientras que en el ámbito de la justicia, la jurisprudencia es trascendental, en el de la formación del conocimiento es peligrosa si te sometes a ella.

E. B.: El compromiso del investigador también tiene que ser más profundo.

J. M. C.: Claro, absolutamente...

R. T.: ¿Podrías comentar un poco sobre lo absurdo de hoy en día en relación al dominio de la imagen, como se puede usar, a quien pertenece...?

J. M. C.: Si, te refieres a los derechos de autor. Hay un problema clarísimo: el concepto de "derechos de autor" pertenece al siglo XIX, y se está aplicando a rajatabla en un momento en el que la tecnología ha creado un nuevo terreno de juego. Se está produciendo una profunda controversia que no se puede resolver ni judicial ni policialmente, que es como se está haciendo. Existe un gran problema: en su día, los derechos de autor aparecieron para proteger a los autores de la rapiña de las editoras (estas no pagaban derechos, piratean, cometían abusos, etc.). Hoy en día es al revés, los derechos de autor están ahí para proteger principalmente a los productores. Esta protección es necesaria, pero debe matizarse para no eliminar por el camino toda una serie de ventajas no solo culturales, sino también mentales, que han aportado tecnologías como la digitalización. Se debería buscar un consenso entre todos los instrumentos implicados, en lugar de que unos aboguen por el todo gratis, mientras los otros pretenden que se pague por todo, incluso varias veces.

E. B.: Después de ver la película Fogo no mar (Gianfranco Rosi, 2016), se me ocurre una comparación entre ésta y Balseros (Carles Bosch y Josep 
Entrevista a Josep M. Català: de lo melodramático al relativismo: apuntes sobre la naturaleza del documental

Maria Domenech, 2002), en el sentido de personas yendo al mar. Ambos documentales tienen 20 años de diferencia. ¿Podría pensarse en una comparación fílmica? ¿Y qué habría cambiado en este tiempo?

J. M. C.: Si, si, puede hablarse de una comparación. Cuando un tema es susceptible de suscitar emociones, es decir, cuando es melodramático, la tentación de filmar es muy grande porque los resultados son inmediatos. Es un material que tiene una intensidad y que, por poco que le añadas, va a llegar al espectador.

En cuanto a las diferencias entre ambas producciones producidas por el paso del tiempo, quizás las podemos encontrar en el enfoque: existe una intención más poética, y acercamiento más sutil en Fogo no mar que no estaba en Balseros. Balseros era más televisiva, es decir, pertenecía, a pesar de su ambición, más al ámbito del reportaje, por su estilo, que al del documental propiamente dicho. En Fogo no mar hay una textura fotográfica muy cuidada, con voluntad expresiva, por ejemplo, en las escenas nocturnas; los personajes están construidos dramáticamente, etc.

Esto es interesante porque hay cosas que solo pueden apreciarse con el paso del tiempo. Cuando lo ves en su momento, te paree todo muy real, como si no hubiera ninguna mediación entre la realidad y la imagen, pero cuando regresas a ello al cabo del tiempo o simplemente cuando ves una película perteneciente a otra época, te das cuenta de los cambios dramatúrgicos: el sistema de edición ha cambiado, también el de la iluminación o el encuadre. Es entonces que queda claro que entre la realidad y el realismo hay una enorme distancia. Hay que esperar un poco para ver claramente esta distancia.

E. B.: Una curiosidad: en Balseros, las personas estaban separadas, las que estaban en Cuba y las que estaban en Miami. El filme los une a través de las imágenes. En contrapartida, en Fogo no mar, las personas están juntas en una pequeña isla y la película los separa... 